\title{
The Effect of Education on Early Parenthood among Young Canadian Adults
}

Darcy Hango

Centre de la statistique de l'éducation

Statistique Canada

Ottawa, Ontario, Canada

E-mail: darcy.hango@statcan.gc.ca

Céline Le Bourdais

Département de Sociologie

Université McGill

Montreal, Quebec, Canada

\begin{abstract}
We use the Youth in Transition Survey (YITS) to examine the link between education and early parenthood in Canada. Estimates from proportional hazard models reveal that the exit from fulltime schooling increases the risk of becoming a young parent. However, this risk is tempered by the level of education achieved. Other measures related to education indicate that skipping classes increases the risk of early parenthood for men and women, whereas having peers committed to education reduces the risk for both. Yet higher educational aspirations and more extra curricular activities reduce the risk of parenthood, but for women only.
\end{abstract}

Key Words: early parenthood, education, Youth in Transition Survey, event history analysis 


\section{Résumé}

Cet article s'appuie sur l'Enquête auprès des jeunes en transition (EJET) pour examiner le lien existant entre l'éducation et le fait de devenir un jeune parent au Canada. Les résultats issus des modèles à risques proportionnels révèlent que la fin des études à temps plein accroît le risque de devenir un jeune parent. Par contre, ce risque est réduit par le niveau d'éducation atteint. D'autres mesures associées à l'éducation indiquent que le fait de manquer des cours accroît le risque de devenir un jeune parent chez les hommes et les femmes, alors que le fait d'avoir des amis ayant un niveau élevé d'engagement académique en réduit le risque. Par ailleurs, des aspirations scolaires plus élevées et un nombre plus élevé d'activités parascolaires réduisent le risque de devenir un jeune parent, mais seulement chez les femmes.

Mots clés: parentalité précoce, éducation, Enquête auprès des jeunes en transition, analyse des transitions

\section{Introduction}

Teen parenthood has not received as much attention in Canada as it has in the United States. As a result, when researchers and policy makers want to address this issue in Canada they often must refer to research based on American surveys. This strategy is useful for comparative purposes, but unfortunately may lead to a biased understanding of the situation in Canada, due to differences in racial/ethnic composition and in the frequency of early parenthood. Hence, as Dillon (2001: 26) remarked, "too much of what is known about teen pregnancy in Canada is extrapolated from studies conducted in the United States [and this] has led to a public perception that the rate of teen pregnancy in Canada is similar". However, we know that a larger proportion of American adolescents will experience a birth compared to their Canadian counterparts. For instance, Singh and Darroch (2000) estimated that in 1995 the teenage birth rate in the United States was 54 per 1000 while it was only 24 per 1000 in Canada. This places Canada towards the middle-to-low end of the scale rating teen parenthood among industrialized countries, while the United States stands at the high end.

Past research has found a strong link between socioeconomic disadvantage and risk of an early birth (Furstenberg 2003; Hobcraft and Kiernan 
places Canada towards the middle-to-low end of the scale rating teen parenthood among industrialized countries, while the United States stands at the high end.

Past research has found a strong link between socioeconomic disadvantage and risk of an early birth (Furstenberg 2003; Hobcraft and Kiernan 2001; Kiernan 1997; Singh, Darroch and Frost 2001). Of particular relevance is the influence of education (Glick, Ruf, White and Goldscheider 2006). For instance, Ravanera and Rajulton (2006) found a general positive association between high socioeconomic status and delaying of childbirth in Canada. In addition, past research has shown that Canadian young unmarried mothers see their education severely curtailed, with the majority of women who had a birth in high school never returning to complete their degree (Clark, Dechman, French and MacCallum 1991). Early parenthood has been studied especially among women, yet some research suggests similar results for men (Nock 1998; Sigle-Rushton 2005).

The current paper uses a recent Canadian longitudinal survey on young adults to examine the impact of education on the likelihood of early parenthood. We specifically address whether the risk of early parenthood is affected by exit from full time schooling, level of education achieved, as well as by processes related to educational commitment, academic performance and parental and peer influences during high school. We analyze these relationships separately for men and women.

\section{Background}

Past work has shown that being enrolled in school greatly reduces the risk of becoming a parent in early adulthood (Blossfeld and Huinink 1991; Liefbroer and Corijn 1999). The roles of student and parent appear to be highly incompatible and young adults typically wait to start families until they finish their education. Yet, while these roles are at odds with each other, the processes determining education and parenthood are commonly thought to be jointly determined (Baizán and Martín-García 2006). As a result, the factors which influence educational attainment, may similarly affect the risk of becoming a parent at an early age. For example, "(bad) health or intellectual capacities can affect incentives to invest in education and labour market experience, which in turn influence the economic returns to postponing childbearing" (Baizán and Martín-García 2006: 95).

The level of education that one achieves has also been found to be negatively related to the risk of marrying (Ravanera and Rajulton 2007), or of becoming a parent at a young age (Liefbroer and Corijn 1999). Delay of first parenthood among the more educated individuals can in part be attributed to the considerable opportunity costs associated with motherhood and fatherhood. Time spent on parenting often conflicts, first, with studying requirements and, 
later, with the demands associated with the early stages of a career; consequently, men and women often delay starting their families until their career is more firmly established (Liefbroer and Corijn 1999).

A recent study suggested that the degree of engagement in school could in fact be more important for predicting the timing of family formation than both school enrolment or achieved level of education (Glick, Ruf, White and Goldscheider 2006). Equally important for their future are the youth's educational aspirations as well as the expectations that their parents hold for them in this regard. On the one hand, teens who aspire to achieve high levels of education typically succeed in obtaining higher educational degrees (Hagan, MacMillan and Wheaton 1996), and higher educational expectations have been found to lead young adults to postpone the formation of conjugal relationship (Hango and Le Bourdais 2007), an event that is strongly linked with conceiving a child. On the other hand, having parents who hold high expectations for one's future also yields greater educational achievements (McNeal 1999) and a lower risk of having an early birth (Glick, Ruf, White and Goldscheider 2006). Many of these factors related to parent and student educational aspirations and connectedness are intertwined with the social class of the family. For instance, previous research has shown that part of the association observed between family socioeconomic status and educational achievement is due to the fact that parents of high socioeconomic status tend to be more involved in their children's education and more comfortable and familiar with the education system (Ho Sui-Chu and Willms 1996; Lareau 1987). ${ }^{1}$

Prior research has also focused on the influence that peers, residential mobility, and the frequency of participating in extracurricular activities exert on educational outcomes, as well as on the likelihood of having an early birth. Peers especially were shown to have a strong influence on educational related decisions during the teenage years (Brooks 2003): adolescents tend to perceive their future and the transition to adulthood in concordance with their peers' view on that matter (Kandel and Lesser 1969; Seltzer and Waterman 1996). Hence, young adults who are surrounded by friends who place a high value on education may be exposed to attitudes conducive for the postponement of childbearing.

The effects of residential mobility on child and youth well-being are well established. Coleman (1988) argued that family mobility may sever important community and extra-familial ties which, in turn, can adversely affect educational attainment. More recent research supports this finding (Hagan, MacMillan and Wheaton 1996; South, Haynie and Bose 2007; Pribesh and Downey 1999). Residential mobility has also been found to be closely associated with behavioural problems (Dewit, Offord, and Braun 1998; Wood, Halfon, Scarlata, Newacheck and Nessim 1993; Simpson and Fowler 1994), teen pregnancy and sexual activity. For instance, Stack (1994) found that among 15-19 year old girls, the odds of having sex for the first time increased with each 
successive move a family made, while Sucoff and Upchurch (1998) found that two or more residential moves between ages 11 and 16 increased the hazard of having a birth before age 20 .

Lastly, several studies have shown that extracurricular activities increase test scores (Cooper, Valentine, Nye and Lindsay 1999), as well as overall academic performance (Broh 2002; Gerber 1996; Zaff, Moore, Papillo and Williams 2003). Extracurricular activities were also found to be linked with greater educational attainment (Eccles and Barber 1999) and with a reduced risk of dropping out of high school (Mahoney and Cairns 1997). Similarly, other researchers have found that church and volunteer work reduce the risk of antisocial behaviour (Eccles and Barber 1999), and that school extracurricular activities buffer adolescents from exhibiting antisocial behavioural tendencies (Mahoney 2000). Little work has, however, examined the direct link between extracurricular activities and adolescents' sexual behaviour. One exception is a study carried out in western New York State, which found that sport participation in high school reduced the risk of sexual activity, but only for girls (Sabo, Miller, Farrell, Melnick and Barnes 1999). These authors suggest that girls who participate in sports may have increased self-esteem, a trait that is linked with a lower risk of having a teenage pregnancy.

In this study, we attempt to shed light on the extent to which educational factors in Canada affect the risk of becoming a parent in early adulthood. We focus on education, both in terms of school enrolment status and level of education achieved, as well as in terms of aspirations and engagement during high school. The inclusion of such measures during adolescence is important as it allows us to highlight potential areas of intervention during school years in order to reduce the risk of becoming a young parent. We focus separately on young men and women because of the differential prevalence and consequences of early parenthood between the two groups.

\section{Data and Method}

\section{Data}

The data we use come from the Youth in Transition Survey (YITS). The YITS is designed to provide policy relevant data on transitions from school to work among young adults in Canada. It collects very rich information on education and provides dates of educational enrolment and educational transitions, such as high school graduation, start of a post-secondary program as well as graduation from a post-secondary program (Bowlby and McMullen 2002; Zeman, Knighton and Bussière 2004). The YITS also contains useful information on the date of birth of dependent children. 
This data set is representative of the Canadian population and has two target samples that are followed every two years: (1) a cohort of individuals who were 18 to 20 years old on December $31^{\text {st }}, 1999$, and (2) a cohort of students who were age 15 on December $31^{\text {st }}, 1999$. We use the 18 to 20 year old cohort since our interest is on early parenthood, which is more common amongst this older sample. To analyze the factors affecting the risk of parenthood in early adulthood we use data from Cycles 1 and 2 collected during the years 2000 and 2002. ${ }^{2}$ We capitalize on this longitudinal design and use an event history approach to study education and timing of first birth over time. The YITS is useful for studying the processes leading to early parenthood since Cycles 1 and 2 focus on respondents under age 23, an age limit that is well below the median age of first birth (almost age 30) in Canada (Ravanera, Rajulton and Burch 1998; Ravanera, Rajulton, Burch and Le Bourdais 2002).

The YITS is based upon a complex stratified sample design with multiple stages and unequal probabilities of selection; therefore, in order for estimates and their standard errors to be unbiased we adopt an appropriate weighting strategy (see the Method section below).

The original sample size in Cycle 1 comprises 22,378 respondents; by Cycle 2, almost $16 \%$ of them $(3,599$ cases $)$ had left the sample, resulting in 18,779 respondents (Bowlby and McMullen, 2002). However, as we adopt a life course approach using information from both cycles, the attrition rate is not as severe in our analysis since our time dependent measures allow for different end-of-observation points, while our time constant measures are from Cycle $1 .{ }^{3}$ The initial sample size of 22,378 decreases to 20,789 as a result of (1) missing data across all model variables (1576 cases) and (2) restricting the analysis to births occurring at age 15 or older (13 cases). Almost half of the missing information (close to 680 cases) is due to not knowing the timing of the first union or first birth. We conducted separate analyses to test whether the respondents with missing data on the dependent variable (i.e. age of birth) ${ }^{4}$ or any of the independent variables ${ }^{5}$ significantly differ from those with no missing data, and found very few differences. Consequently, cases with missing data are excluded from the analytical sample used in the following models, which comprises 10,302 women and 10,487 men.

\section{Dependent Variable}

We use Cox proportional hazard models to examine the impact of education and other pertinent factors on the risk of becoming a parent prior to age 23. The data file provided by Statistics Canada contains a variable that indicates the age of each dependent child for whom a respondent 'is financially responsible and/or has sole or joint legal custody.' This variable covers both biological and nonbiological (adopted, step or foster) children. Only biological children are 


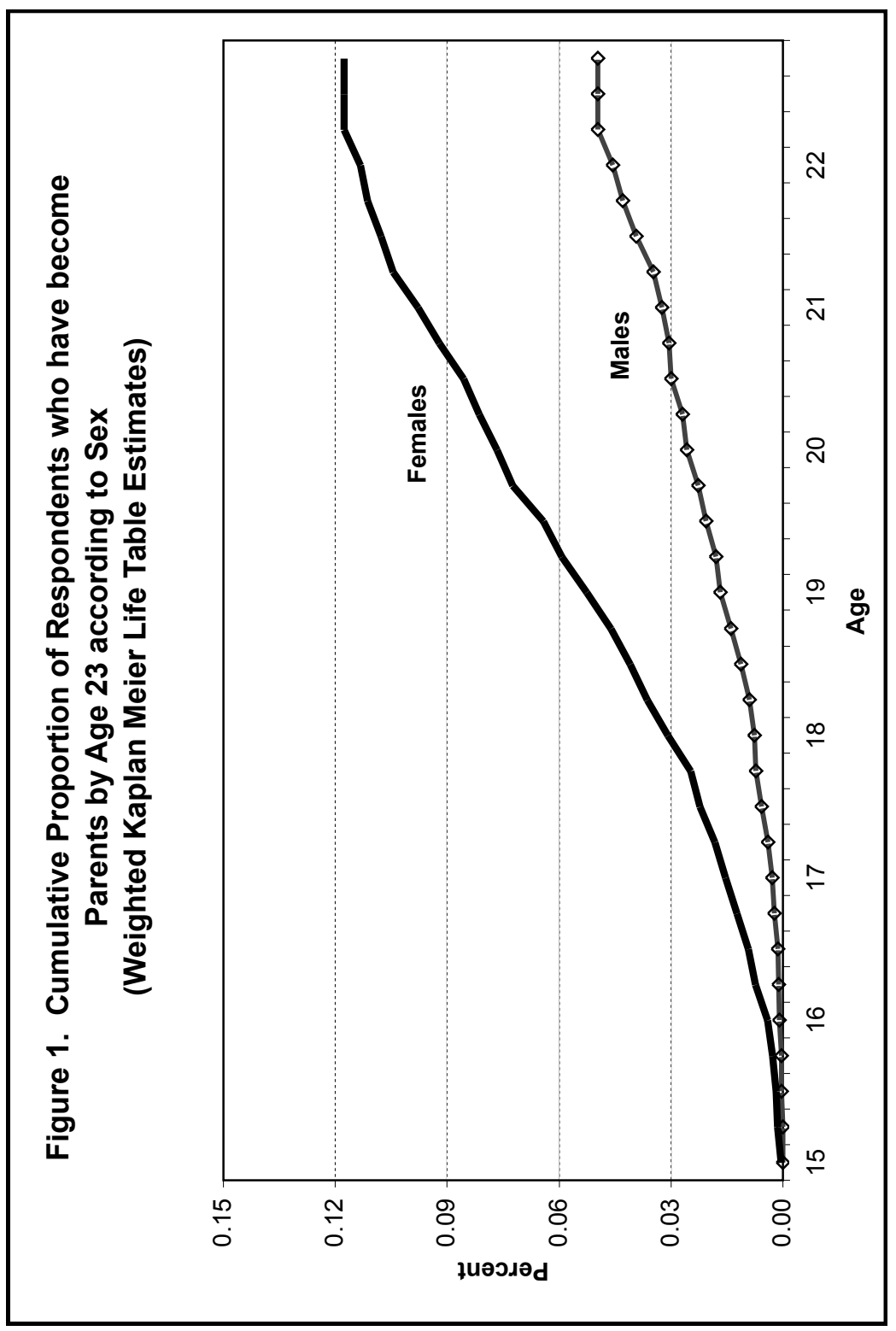

CSP 2009, 36.3-4: 237-265 
retained in our analysis, while a small number (approximately 50) of nonbiologically related children have been excluded from our sample. Moreover, similar to previous work (see Goldscheider, Hogan and Turcotte 2006), we also use the $1^{\text {st }}$ month of pregnancy rather than the date of the birth as our measure of timing of parenthood (that is, we use 8 months prior to the birth of the child as our dependent variable).

Births prior to age 15 are extremely rare in the YITS, and we restrict our analysis solely to those occurring at age 15 and older. The time span during which respondents are at risk of having a birth thus ranges from age 15 up to and including age 22 for the older cohort members. Kaplan-Meier life table estimates presented in Figure 1 show that approximately $12 \%$ of the young women and $5 \%$ of the young men reached by YITS reported having a biological child prior to age 23. The cumulative proportion of women who had a child is consistently about twice as large as that of men at any age. For example, by age 19 , less than $2 \%$ of men reported they ever had a child, compared to slightly over $5 \%$ of women. One should note that only live births, which have not been given up for adoption by respondents, are captured in this survey. Moreover, no information was collected on conceptions leading to an abortion. Our dependent variable thus measures the risk of conception (or more specifically, the risk of pregnancy eight months prior to the birth of the child) only for those resulting in live births and not given for adoption.

Measuring parenthood at these young ages is clearly a selective process that varies with age, as the risk of different types of outcomes associated with a pregnancy changes as the adolescent ages. For instance, Dryburgh (2000) estimated that abortion is the most common outcome for pregnancies occurring among women aged 15 to 17 , while the majority of pregnancies among women aged 17 and above are more likely to result in a live birth. In this analysis, we are thus focusing on a select group of adolescents who chose a less common conclusion to their pregnancy since they decided to keep their baby after giving birth, especially for females who had a child at a very young age.

\section{Independent variables}

In our models, we introduce various education variables measuring school enrolment, level of education achieved, educational ability, commitment and aspirations, as well as indicators measuring social capital and peer influence. Specifically, we consider two time varying indicators that measure exit from full-time schooling and the level of education completed. In both cycles, respondents are asked about the last month they were enrolled in school full time, which could have been at either the high school or postsecondary level. They are also asked the month they graduated from high school, started a postsecondary program, or graduated from a postsecondary program. 
The enrolment indicator specifies whether or not the respondents had left school on a full time basis. For the majority of respondents, this indicator first takes the value of 0 since most are attending school full time when the observation starts at age 15; it then changes to 1 when they stop going to school full time. To be certain we are accurately measuring the actual end of full time studies (and not summer vacation absences), we add six months onto the last month given by the respondents (see Coppola, 2004 for a similar method). This procedure is also necessary since in this dataset enrolment status is asked in December of the year prior to the survey. For example, Cycle 1 was carried out between January and March 2000 and enrolment information ceased in December 1999. Similarly, Cycle 2 was completed between February and June 2002 and enrolment was asked in December 2001.

Our second time varying education measure ascertains the level of schooling that respondents have achieved. We use four categories, which take different values for individuals as they complete successively higher levels of education: (1) less than high school (reference), (2) high school diploma, (3) some post secondary education (which indicates that they have started a program but have not yet completed it), and (4) post secondary degree or diploma (which could have been either a four year bachelor's degree or a two year college or trade diploma). Similar to the exit from full time school measure, for this measure we also added six months onto the date respondents stated each level of education was achieved, that is, if a respondent said they completed all high school requirements by January, we added six months onto that date.

As measures of educational commitment, we include grade point average, frequency of skipping classes, and number of hours spent each week in extracurricular school activities during the last year of high school. We focus on school related extracurricular activities as they were found to have a much stronger effect on academic achievement than nonschool related activities (Chambers and Schreiber 2004). The grade point average is measured in five categories: (1) less than 60\% (reference); (2) 60-69\%; (3) 70-79\%; (4) $80-$ $100 \%$; (5) unknown. To the question asking the number of times per month that they skipped or cut classes without permission, respondents were offered five response categories: 'never', 'less than once a month', 'once or twice a month', 'about once a week' and 'more than once a week'. We use this measure (ranging from 0 to 4 ) as a continuous variable in our models. The number of hours per week spent in extracurricular activities is grouped into four categories: (1) none; (2) one to three hours; (3) four to seven hours; (4) eight hours or more.

To take into account the aspirations of both the teens and their parents, we include, first, an indicator of the highest level of education that the respondent would like to obtain. We categorize this measure as follows: (1) high school or less (reference category), (2) some postsecondary, (3) college, trade or other diploma, (4) bachelor's degree or higher, and (5) undecided or do not know. Second, we incorporate a measure, asked of the youth, of how important 
it is to their parents that they 'obtain more than a high school diploma'. The response categories are 'not important at all,' 'slightly important,' 'fairly important,' and 'very important.' We use this measure (ranging from 1 to 4 ) as a continuous variable in our models. In order to capture the influence of peers, we include the number of close friends who mention 'planning to continue their education beyond high school'. The provided response categories are 'none', 'very few', 'some', 'most', and 'all'. We also use this measure (ranging from 1 to 5) as a continuous variable. Finally, to account for the existence of close relationships with others, we add the number of high schools (continuous measure ranging from 1 to 4 or more) that the youth has attended; this measure has often been used as a proxy to control for loss of important relationships when families move, or when children change schools (Coleman 1988).

\section{Other Control Variables}

We include several control measures known to affect both education behaviour and teen parenthood in Canada. First, we include three indicators to capture the respondent's family background: family structure, parental education and number of siblings. In terms of family structure, we utilize information about the parents with whom the respondent lived with most of the time during high school. We use the following categories: both biological parents (reference category), step-family, lone parent family, and all other family types. In terms of parental education, we use the highest level attained by either parent, which allows us to take education in single parent families into account. The specific parental education categories are: less than high school (reference category), high school only, more than high school, do not know the education level of both parents, and in order to be exhaustive, we include a category indicating that the respondent had no parents while in high school. Lastly, the number of siblings ranges from zero to five.

We also take into account a number of cultural indicators, such as language first learned as a child (French, English, neither), country of birth (Canada or outside of Canada) and ethnic background (Aboriginal or nonAboriginal); we include this last indicator because of the higher fertility rate among Aboriginal youth. ${ }^{6}$

Two other important control measures are used to assess regional differences in education and teen parenthood rates (see Dryburgh 2000): urban (as opposed to rural) area in Cycle 1, and province (Quebec, Ontario, other) where the respondent last went to high school. Lastly, due to the strong association existing between childbearing and union formation (Baizán, Aassve and Billari 2003), we include a time varying covariate indicating whether or not respondents were in a union (either marriage or cohabitation) eight months prior to the birth of a child. 


\section{Method}

We use Cox proportional hazards modelling to predict the risk of parenthood prior to age 23 (Cox, 1972). Our dependent measure is defined as the instantaneous rate of entry into first parenthood, and is specified as a function of time constant and time dependent covariates. Cox's semi-parametric regression model, which does not make any assumptions about the shape of the hazard of becoming a parent over time, can be expressed as follows:

$$
r_{(t)}=h_{(t)} \exp (b X)
$$

where $r_{(t)}$ is the rate at which the respondent experiences the hazard of becoming a parent at time $t, h_{(t)}$ is the base-line hazard rate at $t$, and $X$ is a vector of both time constant and time dependent covariates. This instantaneous rate is defined as the ratio of the number of respondents entering parenthood to the number of those who are still at risk of having a first child. For all respondents, the observation period begins at age 15 and ends with the birth (or, more precisely, one month after the conception) of a child, or at the date of the last interview for those who had not yet had a child (censored cases).

To introduce time dependent variables into the models we use the method of episode splitting (Blossfeld, Hamerle and Mayer, 1989; Blossfeld and Huinink, 1991). In this approach, a new episode is created if the characteristic under consideration changes prior to the outcome. For example, with regard to the exit from school, we first define a dichotomous variable which is assigned the value 0 (in school); this variable takes the value of 1 (exit from school) from the moment the individual leaves school, which then marks the beginning of a second episode.

We use the appropriate weight factors provided by Statistics Canada to compute the parameter estimates in our models (Statistics Canada, 2003). To control for the survey clustered design, we estimated the standard errors of the coefficients using a replication approach. All results presented in Tables 2 and 3 reflect standard errors derived from re-sampling each model 1,000 times using the provided bootstrap weights (Statistics Canada 2003). ${ }^{7}$ In all our analyses we use the statistical program Stata Version 10.1 (StataCorp, 2008). ${ }^{8}$ 


\section{Results}

\section{Descriptive}

Table 1 presents the means and standard deviations of all variables used in the analysis. As can be seen, the vast majority of the sample is Canadian born (91.3\%), non-Aboriginal (97.6\%) and have English (61.9\%) as their mother tongue. Most $(73.8 \%)^{9}$ grew up in an intact family where two biological parents were present during their high school years, and nearly $60 \%$ had at least one parent who had achieved more than a high school degree. By the last time they were interviewed, or in the last period preceding the end of the $1^{\text {st }}$ month of pregnancy for those who had a child, approximately $30 \%$ of the respondents (aged 20 to 22 at most) had completed some post-secondary education, but only $4 \%$ had already obtained a degree or diploma; the latter were more likely to have completed short duration programs. At that time, only $5 \%$ of respondents had already entered conjugal life, $4 \%$ through a common-law union and less than $1 \%$ through marriage.

Variables measuring educational commitment and aspiration during high school show that $80 \%$ of respondents had a grade point average of $70 \%$ or more, and that close to $60 \%$ aspired to obtain a bachelor's degree or higher; less than $5 \%$ did, in fact, answer that they expect to complete solely a high school degree or less. The youth's aspirations closely match those of their parents: the mean score of 3.574 indicates that parents, on average, consider that it is 'fairly' or 'very' important that their children obtain more than a high school diploma. Similarly, respondents, on average, declared that 'most' of their close friends plan on continuing their studies beyond high school. The pattern of extracurricular activity appears to be contrasted: $17 \%$ of youth reported spending eight or more hours per week in extracurricular school activities in the last year of high school, and a similar percentage reported four to seven hours; at the other end, roughly $40 \%$ mentioned devoting no time to such activities. Unfortunately, we do not know the exact nature of these activities (for instance, whether they are related to sports, arts or music); we only know that they are school extracurricular activities, as opposed to non-school activities. Nonetheless, we expect to find participation in those activities to a certain extent to be associated with connectedness to the education system. Broh (2002), for instance, found that various forms of extracurricular activities were linked with educational achievement. The strongest link was with sports, yet participation in music, school councils, school drama clubs and cheerleading also turned out to be important. Our measure, while lacking this level of detail, should nevertheless prove useful since it tallies up the total number of hours spent on all types of school extracurricular activities.

CSP 2009, 36.3-4: 237-265 


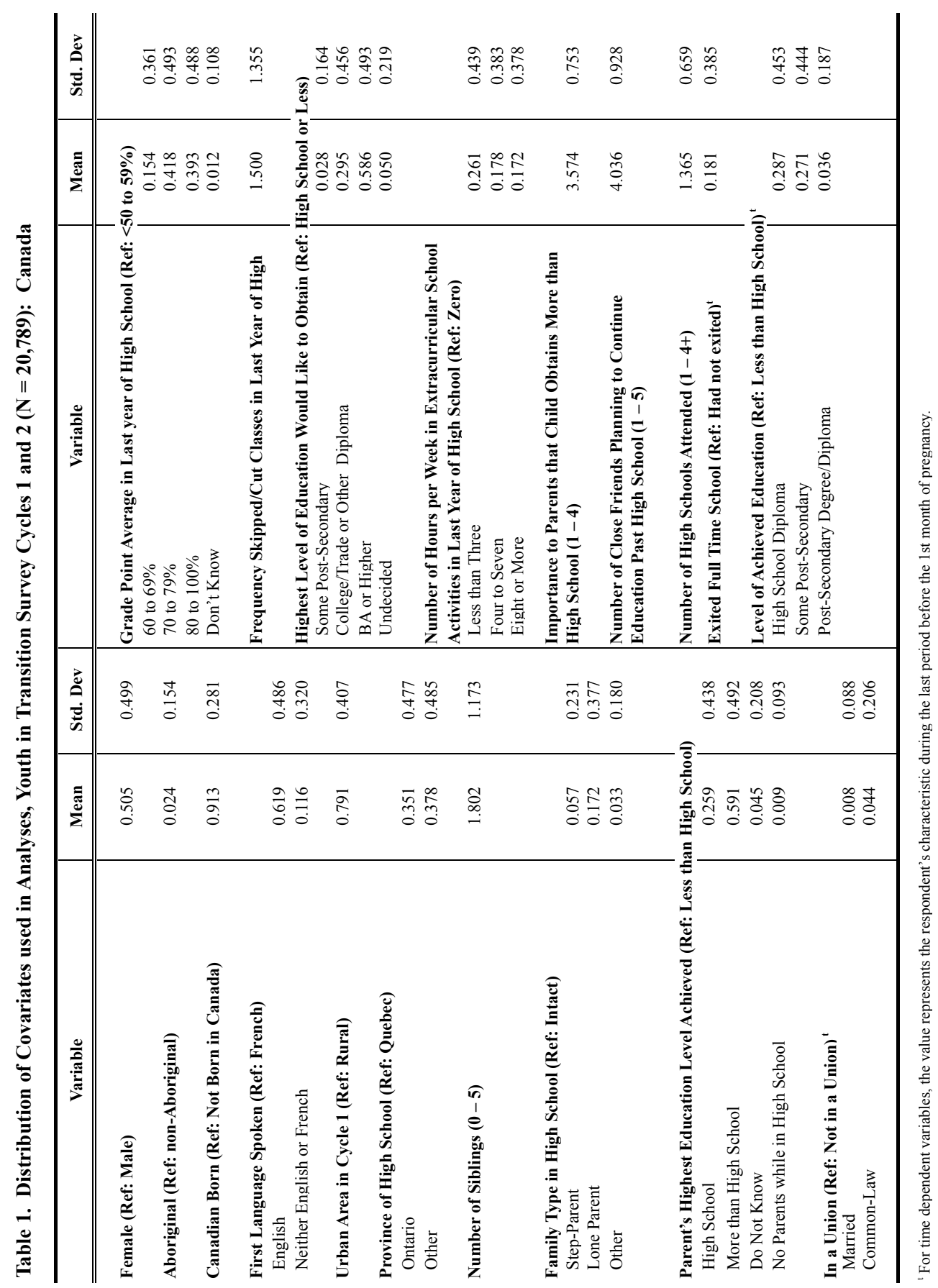




\section{Cox Proportional Hazard Models}

Tables 2 and 3 present, separately for females and males respectively, the parameter estimates predicting the risk of becoming a parent prior to age 23 derived from proportional hazard models. We estimate six different models. Model 1 only includes basic demographic variables to which family and parent related variables are added in Model 2. In the three following models, three sets of variables are separately introduced. Model 3 introduces the four indicators related to educational ability, aspirations and engagement. Model 4 includes the three indicators measuring parental and peer effects, and Model 5 includes the time-varying covariates taking into account exit from full time schooling and achieved level of education. Lastly, in Model 6, we include all the educational as well as control variables. Our estimates are presented as hazard ratios $\left(\mathrm{e}^{\beta}\right)$ for ease of interpretation.

\section{Educational Engagement and Aspirations}

Tables 2 and 3 (Model 3) show that the youth's educational engagement and aspirations are directly linked to their likelihood of having a first child. The risk of becoming a young parent increases as the relative frequency of skipping/cutting classes increases, and this relation holds for both men and women. For each point increase on the scale measuring this dimension, women see their chances to have a child raised by $13.9 \%$, and men by almost $20 \%$ (Model 3). For both sexes, the effect of this variable is slightly reduced when all other education factors are included in the equation, but nonetheless remains statistically significant (Model 6).

Grade point average, which reflects ability in addition to commitment, also appears to be significantly related to early parenthood, though to a lesser extent. Generally, the risk of becoming a parent decreases as the teen's grade point average increases. However, only females who received a mark of $80 \%$ or more experience a risk that remains significantly lower than those who obtained less than $60 \%$, once all other factors are included in the equation (Model 6).

The level of education that respondents declared they would like to obtain is also negatively associated with their chances to have a first child, and more so for women than for men. When compared to women who expect at most to receive a high school diploma (reference category), those who aim to complete some post-secondary education see their chances of becoming a parent reduced by approximately one third, and those expecting to obtain a bachelor's or higher degree, by about two thirds (Model 3). These effects are weakened when all other educational indicators are controlled for. In this case, only women with the highest educational expectations significantly differ from the reference category in their risk of early parenthood (Model 6). As for men, the significant effect 


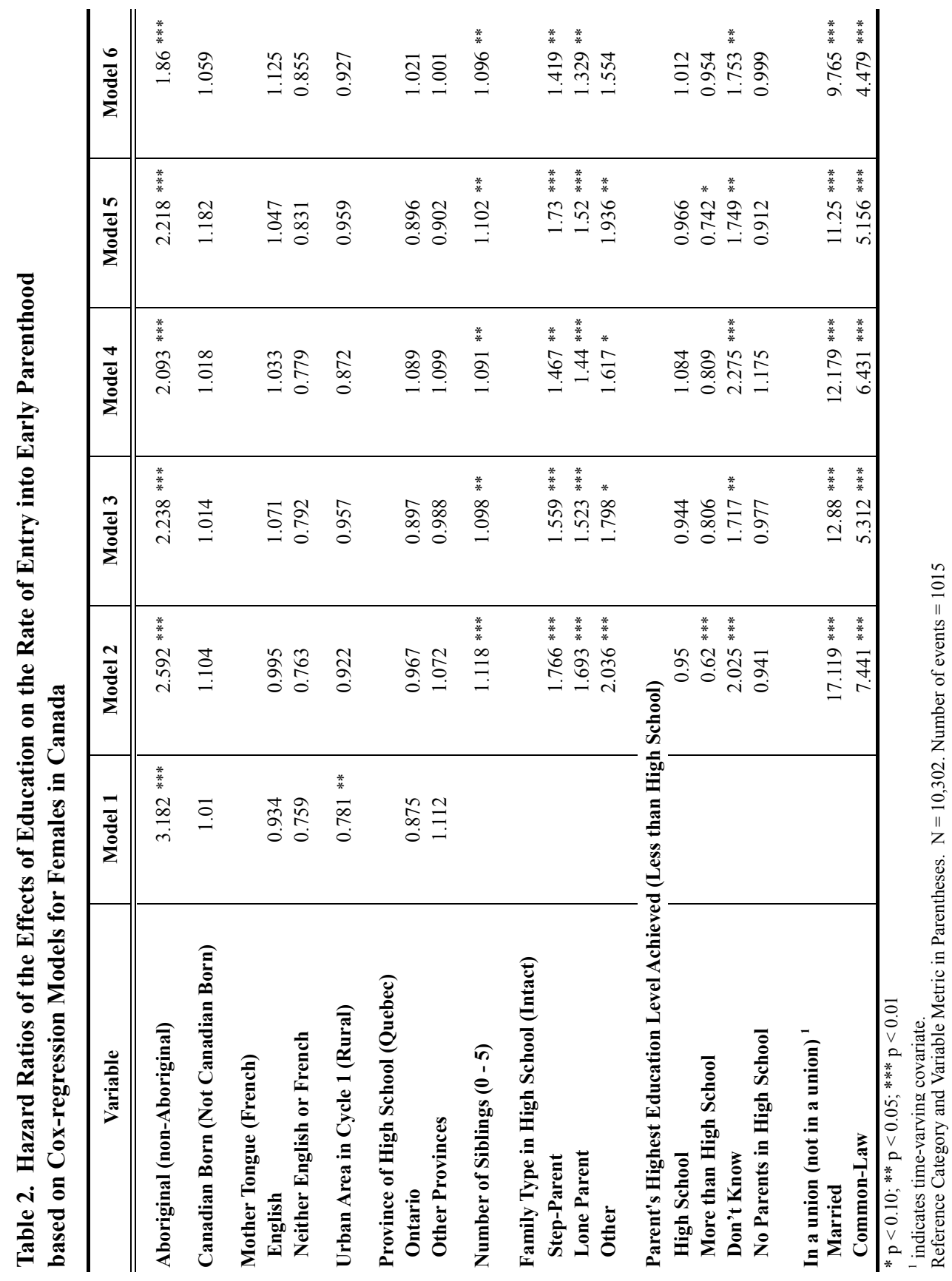




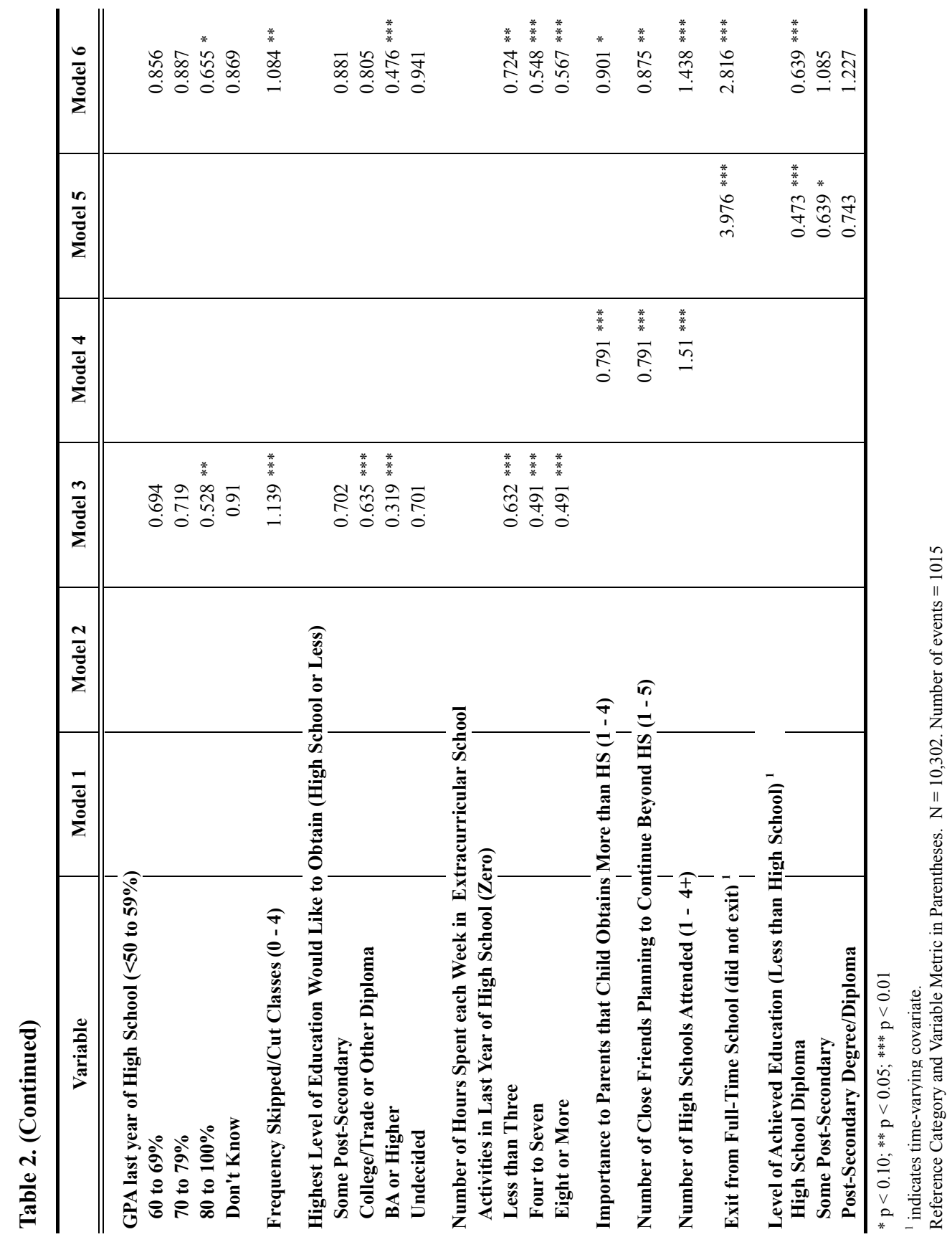




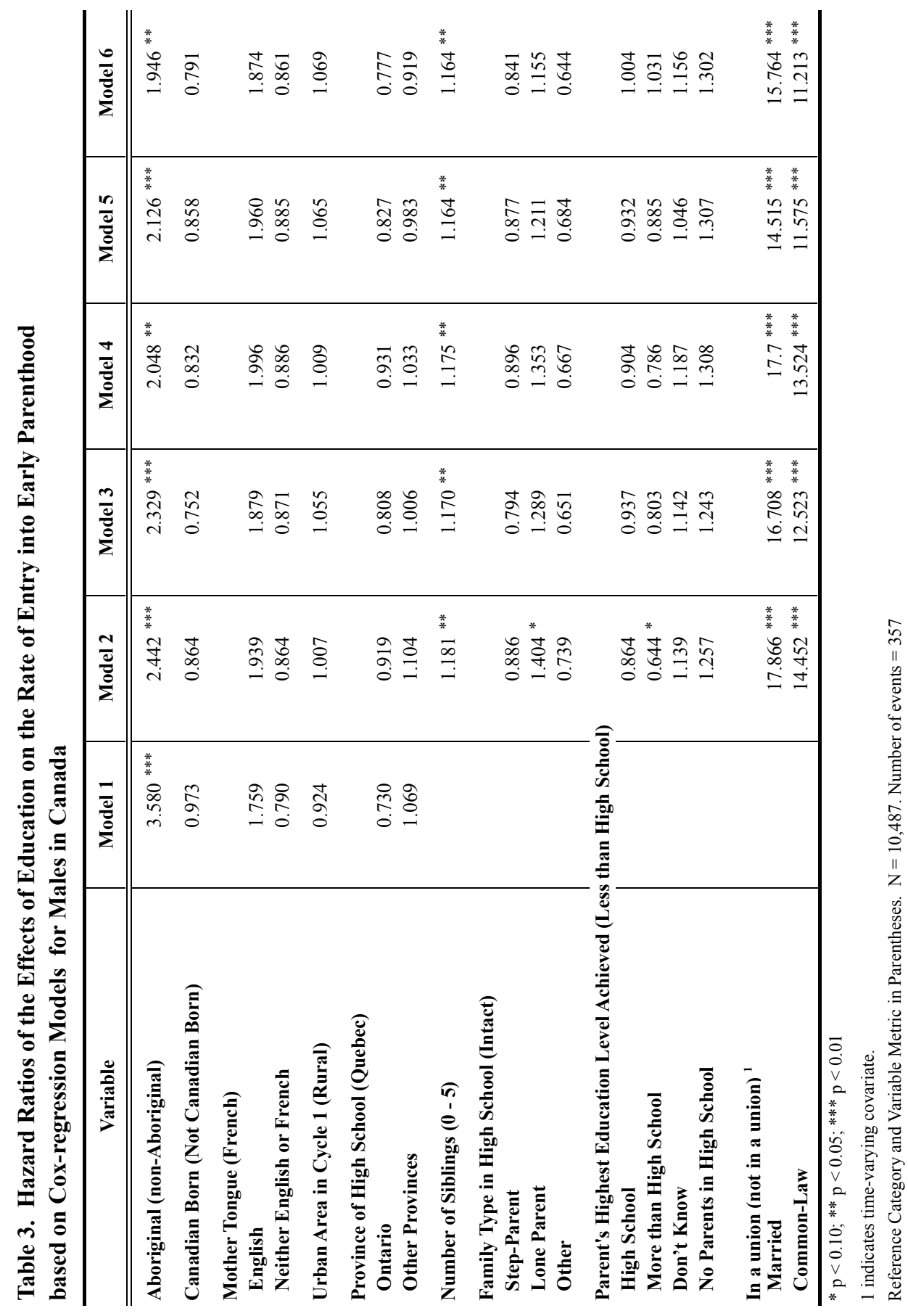

CSP 2009, 36.3-4: 237-265 


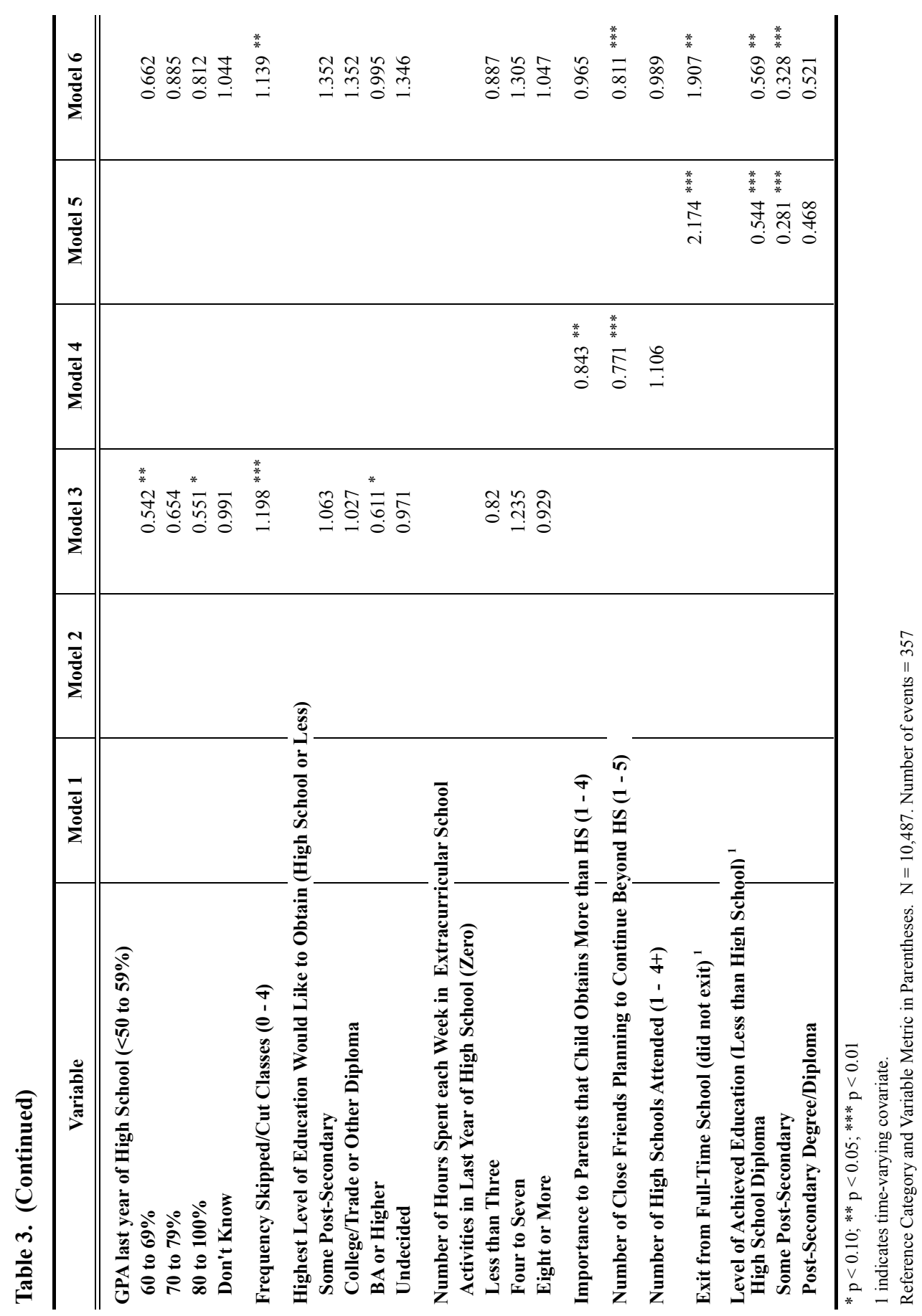

CSP 2009, 36.3-4: 237-265 
detected in Model 3 for those aspiring to obtain at least a bachelor degree vanishes when all covariates are included in the model.

Lastly, the effect of extracurricular activities proves to be robust for women, even with the inclusion of the other educational controls, while for men it is never significant. In the full model, women who spent between one to three hours per week in extracurricular school activities have $28 \%$ less chances to have an early birth than those who did not devote any time to such activities, and women who spent four or more hours per week have approximately $45 \%$ less chances to do so. Hence, it appears that time spent in extracurricular activities reduces the risk of early parenthood for women, whereas for men the effect is nonexistent.

\section{Parents' and Friends' Influences}

Model 4 aims at measuring parents' and friends' influences on the likelihood of early parenthood. It first shows that the importance placed on higher education by parents affects the youth's future, but more so for daughters than for sons. For each one point increase on the scale rating the importance that their parents place on completing post-secondary education, daughters see their risk of becoming a young parent reduced by almost $20 \%$, and sons by approximately $15 \%$. However, this effect completely disappears for men and is cut by half for women in Model 6 when all other covariates are included in the equation.

During high school, the influence of close friends can be quite important in affecting the youth's decisions related to all facets of their life, including education. Our analysis confirms this expectation. Tables 2 and 3 show a strong positive relationship for both men and women between the risk of early parenthood and the fraction of one's close friends who plan to continue their education beyond high school, and this association remains significant even after including all other education variables. Model 6 shows that young men see their risk of becoming a parent decrease by nearly $20 \%$ as the relative number of their friends who plan to pursue education beyond high school increases. The effect is stronger for males than females, whose risk is reduced by $13 \%$ with each point increase on the scale indicating the proportion of their friends aiming to complete some post-secondary education.

As a proxy measure of loss of important relationships, we expected the number of high schools attended by the youth to be positively linked with the risk of early parenthood. The analysis reveals that this is indeed the case for women, but that this variable exerts no significant effect for men in any models. For women, the risk of becoming a young parent increases by $44 \%$ with each new school attended, after controlling for all other covariates (Model 6). 


\section{Exit from Full-Time Education and Achieved Level of Education}

Model 5 introduces the two time-varying indicators measuring school enrolment and achieved level of education. As expected, the risk of becoming a parent appears to be strongly linked to exit from full-time education for both men and women. This effect remains statistically significant regardless of other factors present in the equation and appears to be stronger for women than for men. Hence, from the moment they stop attending school on a full-time basis, women have a risk of becoming pregnant of a child whom they will keep that is almost three times greater (hazard ratio of 2.816) than those who are still enrolled fulltime in school (Model 6). For men, the risk of early parenthood after leaving school is lower, but is substantially higher than for those men who are still in school (hazard ratio of 1.907).

After controlling for full-time school attendance, the level of achieved education generally appears negatively linked to the risk of early parenthood, with respondents who have at least obtained a high school diploma registering lower hazard ratios than those who did not attain this educational level. However, the relationship is not linear and is substantially reduced when all other covariates are included in the equation, especially among women. The full model indicates that women who have obtained a high school diploma have a $36 \%$ lower chance of becoming a parent than those who have not completed high school (Model 6). For men, the effect is similar but stronger: those who obtained a high school diploma have a risk of early parenthood that is $43 \%$ lower than men who do not possess such a diploma, and those who have taken some postsecondary training but who have not yet graduated have a risk that is $67 \%$ lower.

\section{Control Variables}

A series of other measures known to affect both education and risk of early parenthood were also included in the analysis. These measures are present in all models and since their effects do not vary much across models, we discuss only the estimates established in Model 6.

Not surprisingly, the largest hazard ratios are those related to the union formation variable. For example, the fact of getting married multiplies by almost ten a woman's chances of becoming a parent; the effect of cohabitation is lower but is still associated with a risk of parenthood that is nearly four and a half times greater than that of women who are not living in a union. For men, the effect is even more pronounced. Men who marry have a fifteen times greater risk of becoming a parent than those who are not in a union, while for cohabiting the risk is over eleven times greater. The stronger effect for males may be due to a selection effect since only conceptions resulting in live births are taken into 
account; in other words, men willing to father a child may be more committed to enter a marriage or a common-law union.

We included measures of ethnicity and place of birth, and found that Aboriginal men and women are at much higher risk of becoming young parents than non-Aboriginal men and women: the risk is increased by $86 \%$ for women and by $95 \%$ for men. However, neither place of birth nor mother tongue appears to exert a significant effect per se on the risk of early parenthood.

Tables 2 and 3 show that the characteristics of the families in which the respondents grew up are linked to their chances of having a child. Having a large number of siblings increases the risk of early parenthood for both sexes; each additional sibling raises this risk by approximately $10 \%$ for women and $16 \%$ for men. The type of family in which the youth lived during their high school years also affects this risk for females, but not for males. Hence, women who lived in step-parent or lone parent families have respectively $42 \%$ and $33 \%$ greater chances of experiencing an early birth than those who grew up in intact families. Once we control for respondents' educational achievement, commitment and aspirations, parental education does not appear to exert any noticeable influence on the risk of early parenthood, except among young women who did not know their parents' education level: these women face a $75 \%$ higher risk of conceiving a child than those whose parents did not finish high school. Interestingly, prior to the inclusion into the analysis of factors related to the respondent's education, higher parental education was shown to exert a negative impact on the risk of early parenthood for females (see Model 2 in Table 3).

\section{Discussion}

This study aimed to shed light on the process of early parenthood among a recent sample of young Canadians under the age of 23 and focussed more specifically on the multiple influences that education exerts on the risk of having a first child. To do so, we introduced a series of education related variables into the analysis. We measured full-time school enrolment in order to assess the effect that leaving the school system has on the risk of parenthood. We found that exit from full-time education greatly increased the risk of becoming a parent. This result concurs with previous research which suggests that the costs, both monetary and time related, associated with having a child are not conducive for forming a family (Liefbroer and Corijn 1999). Hence, it appears that the roles of student and parent are still viewed as incompatible, and that youth typically wait to have children once they have left the education system.

We also sought to examine the effect that achieved level of education exerts on the risk of early parenthood, once school enrolment is taken into consideration. Education is generally assumed to be negatively related to 
parenthood, that is, more educated youth are expected to delay parenthood until they are more securely established in their career. Our analysis showed that young men who had at least obtained a high school degree were less likely to have an early birth than those who had not achieved such a level of education. The effect of achieved education proves to be much stronger for men than women. Indeed, women who had completed some post-secondary education did not appear to be less inclined to have a first child than their less educated counterparts, once their educational commitment and aspirations were taken into account. This result does in fact suggest that the degree of school engagement is perhaps more important than achieved level of education per se in predicting the timing of family formation among recent cohorts of youth, as shown in a recent American study (Glick, Ruf, White and Goldscheider 2006). The young age of our sample does however prevent us from seeing if this relationship will hold, once women have had sufficient time to complete their postsecondary degrees or diplomas.

To further examine the various effects of education on early parenthood, we introduced several indicators meant to tap into educational commitment or ability, educational aspirations, as well as parents' and peers' influences. These educational measures have rarely been taken into consideration in prior research, and their introduction into our analysis thus constitutes a contribution to enhancing our understanding of the role that various educational factors beyond school enrolment and achieved level of schooling play on the risk of early parenthood.

Similar to Glick, Ruf, White and Goldscheider's results (2006), we observed that a greater degree of engagement in education leads to a reduced risk of becoming a young parent. More specifically, we found that the risk of early parenthood increased as the relative frequency of skipping or cutting classes increased, while that risk decreased as the number of hours spent in extracurricular activities increased.

The latter effect, significant only for women, was also observed in a previous study conducted by Sabo, Miller, Farrell, Melnick and Barnes (1999). As suggested by these authors, extracurricular activities perhaps contribute to increases in women's self-esteem, which in turn reduce their likelihood of having a precocious birth. The effect could also be linked to time availability whereby women (and men) who partake in extracurricular activities are less at risk for behaviour conducive to beginning sexual relationships since they are likely to have more structured and supervised schedules (see Zill, Nord and Loomis 1995). Another explanation, based on the existence of close social relationships, or social capital, could also be advanced. For instance, Broh (2002: 72) states that " $\ldots$ it is possible that sports or other activities, by offering opportunities for the formation and intensification of social ties among students, parents, and the school, also create social capital outside the family." In that sense, one could argue that these enhanced relationships, in turn, could act as a 
protective factor against early sexual behaviour. More research, which clearly goes beyond the scope of this paper, would be required if we want to better understand the underlying mechanisms that are at play here.

Our findings suggest that grade point average exerts mostly an indirect effect on the risk of early parenthood, as coefficients were severely reduced or became statistically non significant when the other education factors were included in the full model.

Youths' aspirations towards achieving high educational levels were shown to reduce the risk of early parenthood, but only for women. Women who expressed the desire to achieve a bachelor's or higher degree had a much lower risk of becoming a parent prior to age 23. This link is probably best explained by the fact that young females who aspire to have a high level of education may take greater precautions in order to meet their future goals; having an early birth would most likely make more difficult the attainment of an advanced degree. Moreover, our analysis revealed that parents' educational expectations are related to the timing of early parenthood. Yet, while we have not explicitly tested for direct and indirect effects, it appears that they operate primarily in affecting their children's educational achievement and commitment, which in turn affect their risk of experiencing early parenthood.

By contrast, the influence of peers appeared to play a larger and more direct role, at least for those planning to continue their education beyond high school. Young men's and women's risk of becoming young parents decreases as the fraction of their close friends who expected to pursue post-secondary education increase.

To assess the impact that the loss of important social ties, due to residential mobility, can exert on the risk of early parenthood, as found in previous research (see Stack 1994, and Sucoff and Upchurch 1998), we included a measure of school mobility experienced during high school. Our findings are similar to those obtained in past studies and showed that the risk of becoming a parent increased as the number of attended schools also increased, but only for women. Why is the propensity of women to have a child early in their life closely linked to school mobility while it is not for men? The answer perhaps is to be found in the greater importance that close social relationships generally take in women's lives. Some past work suggests that the social networks of mobile adolescents tend to have lower expectations concerning their future education than those of non-mobile adolescents (South, Haynie and Bose 2007). If the new circles of friends that females acquire through successive high school changes have lower levels of academic engagement and aspirations and are more likely to be involved in risky behaviours, this might put them at greater risk of becoming a young parent. For males, new peer groups may not have the same influence. Further work would be needed to explore these hypotheses, however. 
In conclusion, this research helps explain the link observed between education and early parenthood among a recent cohort of Canadian young adults. Our results highlight three important aspects of this relationship. First, we established that most youth delay their childbearing until they leave the educational system; this effect was stronger for young women than for young men. Second, even at these young ages, we discovered that a higher level of education reduced the risk of early conception; in this case, the effect was stronger among young men. Third, in general, the risk of early parenthood is closely related to levels of educational engagement and aspirations, and to parental influence for women but not for men. Yet, both young men and women appear to be influenced by the behaviour of their peers.

Our results showed that educational factors differently affect the timing of the transition into young parenthood of men and women. Identifying which educational factors play a protective role and which do not is important if efforts to curtail the risk of early parenthood are to be successful. For example, young women may benefit from a larger offer of extracurricular activities, while men may gain from incentives that help them achieve a higher level of education.

While this research was able to illuminate some crucial aspects of the link between education and early parenthood, it has some limitations. For instance, the data did not allow us to identify conceptions that ended in adoption or abortion; our analysis was restricted to conceptions leading to births, which resulted in the situation of young adults living with a 'dependent child'. Consequently, our results might not directly apply to all youth who experienced a teen pregnancy but only to those who completed the pregnancy and kept the child. Clearly, more research is needed if we are to better understand teen parenthood among Canadian youth.

\section{Acknowledgements}

Please direct all correspondence to Darcy W. Hango, Centre for Education Statistics, Statistics Canada. Main Building, 2000-K, 150 Tunney's Pasture Driveway, Ottawa, Ontario. K1A 0T6 [darcy.hango@statcan.gc.ca]. This paper was presented at the annual meeting of the Canadian Population Society, Saskatoon, 2007. The analysis is based on research carried out in the Quebec Inter-University Centre for Social Statistics as well as at Statistics Canada. The opinions expressed here do not represent the views of Statistics Canada. We would like to acknowledge Benoît Laplante for statistical and modelling assistance.

CSP 2009, 36.3-4: 237-265 


\section{End Notes}

1. For a comprehensive discussion of the link between social origin and educational attainment, see Breen and Jonsson (2005).

2. Cycle 1 was carried out between January and March of 2000, and Cycle 2 was carried out two years later between February and June of 2002.

3. To reduce the number of cases with missing data on the dependent variable, we used information from Cycle 1 if the respondent dropped out before Cycle 2. So, for example, for respondents who had not had a birth by Cycle 1 and dropped out between cycles, we stopped the observation at Cycle 1 and used their age at this cycle as time of censoring, since this is the last piece of information we have. Thus, these individuals, while out of the sample after Cycle 1, still contribute to the risk analysis up to their age at Cycle 1. For those respondents who dropped out after Cycle 1, but had given birth by Cycle 1, we know the timing of birth and so they are not considered as missing either. A similar procedure was followed for the education time varying covariates.

4. To test whether the cases with missing data on the dependent variable (i.e. age at birth) differ from those retained in the analysis, we conducted a logistic regression predicting the probability of being excluded from the analytical sample, with a similar set of covariates to those included in our models. This analysis revealed that the only covariates that significantly affect (at .05 level) the risk of having missing data were that of having an 80 to $100 \%$ average grade in the last year of high school and the frequency of skipping classes in the last year of high school. The former reduces the risk of being in the missing sample, while the latter increases the risk.

5. We also used a logistic regression to test whether the 1756 cases with missing data on any of the independent variables differ from those with no missing data. This analysis revealed a similar pattern to that observed when predicting the probability of having missing data on the dependent variable (see endnote 4), namely that having a high average grade in the last year of high school reduced the risk of missing data, while a greater frequency of skipped classes increased the risk. The results of these logistic regressions are available upon request.

6. Aboriginal background is self-reported and contains youth who self-identify as North American Indian, Métis or Inuit. Furthermore, the YITS only includes the off-reserve Aboriginal population from the ten provinces.

7. For more complete information the reader is advised to consult the user guide for these data (Statistics Canada 2003).

8. Specifically, we use the svy procedure in Stata 10. This latest version of Stata enables us to utilize the 1000 bootstrap weights in YITS for the estimation of Cox Proportional Hazard models. 
9. The difference between $100 \%$ and the sum of percentages who grew up in other types of family $(5.7 \%+17.2 \%+3.3 \%=26.2 \%)$.

\section{References}

Baizán, P., Aassve, A. and Billari, F. C. 2003. 'Cohabitation, marriage, and first birth: The interrelationship of family formation events in Spain', European Journal of Population 19: 147-169.

Baizán, P. and Martín-García, T. 2006. 'Endogeneity and joint determinants of educational enrolment and first birth timing in France and West Germany', Genus LXII (2): 89-117.

Blossfeld, H. P., Hamerle, A. and Mayer, K. U. 1989. Event History Analysis. Hillsdale, New Jersey: Erlbaum.

Blossfeld, H. P. and Huinink, J. 1991. 'Human capital investments or norms of role transitions? How women's schooling and career affect the process of family formation', American Journal of Sociology 97: 143-168.

Bowlby, J. W. and McMullen, K. 2002. At a Crossroads: First Results for the 18 to 20Year-Old Cohort of the Youth in Transition Survey. Ottawa: Human Resources Development Canada and Statistics Canada, 81-591-XPE.

Breen, R. and Jonsson, J.O. 2005. 'Inequality of opportunity in comparative perspective: recent research on educational attainment and social mobility', Annual Review of Sociology 31: 223-243.

Broh, B. A. 2002. 'Linking extracurricular programming to academic achievement: Who benefits and why?' Sociology of Education 75: 69-91.

Brooks, R. 2003. 'Young people's higher education choices: The role of family and friends', British Journal of Sociology of Education 24(3): 283-297.

Chambers, E.A. and Schreiber, J.B. 2004. 'Girls' academic achievement: varying associations of extracurricular activities,' Gender and Education 16(3): 327-346.

Clark, S., Dechman, M., French, F. and MacCallum, B. 1991. Mothers and Children: One Decade Later. Halifax: Nova Scotia Department of Community Services.

Coleman, J. S. 1988. 'Social capital in the creation of human capital', American Journal of Sociology 94: S95-S120.

Cooper, H., Valentine, J., Nye, B. and Lindsay, J. 1999. 'Relationship between five after-school activities and academic achievement', Journal of Educational Psychology 91(2): 369-378. 
Coppola, L. 2004. 'Education and union formation as simultaneous processes in Italy and Spain', European Journal of Population 20: 219-250.

Cox, D. R. 1972. 'Regression models and life tables (with discussion)', Journal of the Royal Statistical Society, Series B 34: 187-220.

Dewit, D. J., Offord, D. R., and Braun, K. 1998. The Relationship Between Geographic Relocation and Childhood Problem Behaviour. Working Paper (\#W-98-17E) from Applied Research Branch Strategic Policy. Human Resources Development Canada.

Dillon, M. E. 2001. "Canada.” pp. 15-27 in Teenage Pregnancy: A Global View, A. L. Cherry, M. E. Dillon, and D. Rugh (eds.). Greenwood Press: London.

Dryburgh, H. 2000. 'Teenage Pregnancy', Health Reports, Statistics Canada, Catalogue 82-003, 12(1): 9-19.

Eccles, J. and Barber, B. 1999. 'Student council, volunteering, basketball or marching band: What kind of extracurricular involvement matters?' Journal of Adolescent Research 14(1): 10-43.

Furstenberg, F. F. 2003. 'Teenage childbearing as a public issue and private concern', Annual Review of Sociology 29: 23-39.

Gerber, S. 1996. 'Extracurricular activities and academic achievement', Journal of Research and Development in Education 30(1): 42-50.

Glick, J. E., Ruf, S. D., White, M. J. and Goldscheider, F. 2006. 'Educational engagement and early family formation: Differences by ethnicity and generation', Social Forces 84(3): 1391-1415.

Goldscheider, F. K., Hogan, D., and Turcotte, P. 2006. 'The other partner: The changing role of good provider for men's union formation in industrialized countries', Canadian Studies in Population 33(1): 25-48.

Hagan, J., MacMillan, R., and Wheaton, B. 1996. 'New kid in town: Social capital and the life course effects of family migration on children', American Sociological Review 61: 368-385.

Hango, D. W. and Le Bourdais, C. 2007. 'Early union formation in Canada: Links with education', European Journal of Population 23: 339-368.

Ho Sui-Chu, E. and Willms, J.D. 1996. 'Effects of parental involvement on eighth-grade achievement', Sociology of Education 69: 126-141.

Hobcraft, J. and Kiernan, K. 2001. 'Childhood poverty, early motherhood and adult social exclusion', British Journal of Sociology 52(3): 495-517. 
Kandel, D. B. and Lesser, G. S. 1969. 'Parental and peer influence on educational plans of adolescents', American Sociological Review 34(2): 213-223.

Kiernan, K. 1997. 'Becoming a young parent: A longitudinal study of associated factors', British Journal of Sociology 48(3): 406-428.

Lareau, A. 1987. 'Social class differences in family-school relationships: the importance of cultural capital', Sociology of Education 60: 73-85.

Liefbroer, A. C. and Corijn, M. 1999. 'Who, what, where and when? Specifying the impact of educational attainment and labour force participation on family formation', European Journal of Population 15: 45-75.

Mahoney, J. 2000. 'School extracurricular activity participation as a moderator in the development of antisocial patterns,' Child Development 71(2): 502-516.

Mahoney, J. and Cairns, R. B. 1997. 'Do extracurricular activities protect against early school dropout?' Developmental Psychology 33(2): 241-253.

McNeal, R. B. Jr. 1999. 'Parental involvement as social capital: Differential effectiveness on science achievement, truancy, and dropping out', Social Forces 78(1): 117-144.

Nock, S. L. 1998. 'The consequences of premarital fatherhood', American Sociological Review 63(2): 250-263.

Pribesh, S. and Downey, D. B. 1999. 'Why are residential and school moves associated with poor school performance?’ Demography 36:521-34.

Ravanera, Z. R. and Rajulton, F. 2007. 'Changes in economic status and timing of marriage of young Canadians', Canadian Studies in Population 34(1): 49-67.

Ravanera, Z. R. and Rajulton, F. 2006. 'Social status polarization in the timing and trajectories to motherhood', Canadian Studies in Population 33(2): 179-207.

Ravanera, Z. R., Rajulton, F. and Burch, T. K. 1998. 'Early life transitions of Canadian women: A cohort analysis of timing, sequences, and variations', European Journal of Population 14: 179-204.

Ravanera, Z. R., Rajulton, F., Burch, T. K. and Le Bourdais, C. 2002. 'The early life courses of Canadian men: Analysis of timing and sequences of events', Canadian Studies in Population 29(2): 293-312.

Sabo, D. F., Miller, K. E., Farrell, M. P., Melnick, M. J., and Barnes, G. M. 1999. 'High school athletic participation, sexual behavior and adolescent pregnancy: A regional study', Journal of Adolescent Health 25: 207-216. 
Seltzer, V. C. and Waterman, R. P. 1996. 'A cross-national study of adolescent peer concordance on issues of the future', Journal of Research on Adolescence 11(4): 461-482.

Sigle-Rushton, W. 2005. 'Young fatherhood and subsequent disadvantage in the United Kingdom', Journal of Marriage and the Family 67(3): 735-753.

Simpson, G. and Fowler, M. G. 1994. 'Geographic mobility and children's emotional/behavioral adjustment and school functioning', Pediatrics 93:303309.

Singh, S., Darroch, J. E. and Frost, J. J. 2001. 'Socioeconomic disadvantage and adolescent women's sexual and reproductive behavior: The case of five developed countries', Family Planning Perspectives 33(6): 251-258, 289.

Singh, S. and Darroch, J. E. 2000. 'Adolescent pregnancy and childbearing: Levels and trends in developed countries', Family Planning Perspectives 32(1): 14-23.

South, S. J., Haynie, D. L., and Bose, S. 2007. 'Student mobility and school dropout', Social Science Research 36: 68-94.

Stack, S. 1994. 'The effect of geographic mobility on premarital sex', Journal of Marriage and the Family 56: 204-208.

StataCorp. 2008. Stata Statistical Software: Release 10. College Station, Texas: StataCorp LP.

Statistics Canada. 2003. Youth in Transition 18-20 Year Old User Guide-Cycle 1. Ottawa: Human Resources Development Canada and Statistics Canada.

Sucoff, C. A. and Upchurch, D. M. 1998. 'Neighborhood context and the risk of childbearing among metropolitan-area black adolescents', American Sociological Review 63(4): 571-585.

Wood, D., Halfon, N., Scarlata, D., Newacheck, P., and Nessim, S. 1993. 'Impact of family relocation on children's growth, development, school function, and behavior', Journal of the American Medical Association 270: 1334-1338.

Zaff, J. F., Moore, K. A., Papillo, A. R., and Williams, S. 2003. 'Implications of extracurricular activity participation during adolescence on positive outcomes', Journal of Adolescent Research 18(6): 599-630.

Zeman, K., Knighton, T. and Bussière, P. 2004. Education and Labour Market Pathways of Young Canadians Between Age 20 and 22: An Overview. Ottawa: Human Resources Development Canada and Statistics Canada, 81-595-MIE.

Zill, N., Nord, C. and Loomis, L. 1995. Adolescent Time Use, Risky Behavior, and Outcomes: An Analysis of National Data. Rockville, Maryland: Westat, Inc. 